\title{
Evaluation of Vacutainer Distribution Conditions
}

\author{
Chang-Eun Park \\ Department of Biomedical Laboratory Science, Namseoul University, Cheonan 31020, Korea
}

\section{진공채혈관의 상태에 따른 평가}

\author{
박창은 \\ 남서울대학교 임상병리학과
}

\begin{abstract}
Pre-analytical variables account for most laboratory errors and many factors affect the results from a patient. Type of tubes facilitated rapid separation and prevented hemolysis upon prolonged storage. However, there were some limitations associated with vacutainer conditions. To circumvent the problems, the comparability of complete blood cell count values was examined using various vacutainers. The results of the analysis showed a large coefficient variation of 0.24 , 0.21 in the value of white blood cells and platelets, and significant correlation was observed between white blood cells, platelets, and the value of red blood cells $(p<0.01)$. In each of the three tubes, compared to the value of platelets, white blood cells, the greatest coefficient variation was $0.27,0.21$. In correlation of the three companies, significant difference was observed in values of white blood cells, platelets, and platelet distribution width $(p<0.01)$, however $\mathrm{G}$ and $\mathrm{B}$, the value of platelets, and platelet distribution width were significantly lower $(p<0.05)$. In conclusion, analysis of vacutainers showed that they were suitable for stability of these analytes under vacutainer conditions.
\end{abstract}

Keywords: Evaluation, Vacutainer

This is an Open Access article distributed under the terms of the Creative Commons Attribution Non-Commercial License (http://creativecommons.org/licenses/by-nc/4.0) which permits unrestricted non-commercial use, distribution, and reproduction in any medium, provided the original work is properly cited.

Copyright @ 2016 The Korean Society for Clinical Laboratory Science. All rights reserved.
Corresponding author: Chang-Eun Park Department of Biomedical Laboratory Science, Namseoul University, 91 Daehak-ro, Seonghwan-eup, Seobuk-gu, Cheonan 31020 Korea

Tel: 82-41-580-2722

Fax: 82-41-580-2932

E-mail: eun2777@hanmail.net

Received: April 28, 2016

Revised $1^{\text {st: }}$ May 9, 2016

Revised $2^{\text {nd. }}$ : May 16, 2016

Accepted: May 16, 2016

\section{서 론}

신뢰성 있는 검사 결과를 얻기 위해서는 선행되어져야 할 것이 분석전 변수들을 올바로 인식하고 해석하는 것이 요구된다. 이를 바탕으로 혈장 및 혈청 검체의 분석에서는 채혈 후 2 시간 이내에서 분리가 이루어져야 하며 장기간 보관시에는 검체의 용혈 등이 심각 한 문제를 일으킨다[1]. 진단검사의학과에서 유용하게 사용되는 혈액 검사를 위한 진공채혈관은 적절한 평가가 선행되어야 한다. 이를 통해 적절한 검체를 채취할 수 있는 용기의 선택은 필수적으 로 요구된다[2,3]. 혈청을 분리하기 위한 진공채혈관의 원심분리과 정을 용이하고 신속하게 분리하기 위한 겔의 사용으로 인한 측정물 질의 안정성 분석 등이 요구되는 제한점이 발생하여 이러한 문제점
을 해결하기 위한 시도가 이루어졌다[4]. 현재 국내에서는 다양한 진공채혈관을 사용하고 있으나, 진공채혈관의 평가를 실시한 보고 는 부족한 실정이다. 특히 최근에는 국내에서도 진공채혈관이 개발 되고 있으므로 그 성능을 평가하는 시스템 도입이 절실한 실정이다 [5,6]. 그 동안 국내에서 보고된 진공채혈관 성능평가는 단회 측정 에 의한 쌍체비교법(paired t-test)이고 유효기간에 따른 선별적인 결과의 영향에 대한 평가는 부족한 점이 많다. 이에 본 연구는 최근 다양한 진공채혈관의 유통 상태에 따른 유효기간별 진공채혈관의 성능 및 유효성을 평가하고자 하며 혈구산정 값을 비교평가하여 임 상적 사용 적합성을 검증하고자 한다. 따라서 진공채혈관의 유효기 간별, 생산자별 보관 및 보존, 성능을 입증 평가하여 그 유용성을 알 리고 분석전 오차의 한 요인으로서 필요성을 대두시키고자 한다. 


\section{재료 및 방법}

\section{1. 대상}

본 연구는 남서울대학교 임상병리학과 재학생을 대상으로 시행 되었다. 연구 참여에 동의한 건강한 지원자 51 명을 대상으로 연구 를 시행하였으며, 채혈 및 검사를 진행하였다. 피험자들은 12 시간 이상의 금식 후 아침에 정맥천자로 채혈하였다. 본 연구는 남서울 대학교 생명윤리심의위원회(IRB)의 승인(NSU-141218-1)을 받 았으며 모든 피험자에게 연구에 대한 서면동의서(informed consent)를 받았다.

\section{2. 채혈 및 평가분석}

모든 검체는 한 종류의 바늘 고정기(needle holder, BD)를 사용 하여 동일한 피검자로부터 3개사의 진공채혈관에 순서대로 혈액 을 채취하여 분석하였다. 평가를 실시한 진공채혈관의 종류는 ethylenediaminetetraacetic acid (EDTA) 진공채혈관으로 성능 을 검증하기 위해 $\mathrm{B}$ 사, $\mathrm{G}$ 사, $\mathrm{S}$ 사의 3 개 제품을 평가하였다. 정밀도 평가(precision test)는 '정맥혈 및 말초혈 채취용기의 검증에 관한 지침'인 CLSI GP34-A [2]에 따라 3개사의 각 3개 로트번호 별로 차 이를 분석하였으며 또한 유효기간의 차이에 따른 비교를 평가하였 다(Table 1). 채혈순서에 따른 검사결과의 차이를 최소화하기 위하 여 15 명은 B사 먼저, 15 명은 $\mathrm{G}$ 사를 먼저, $\mathrm{S}$ 사를 먼저 채혈하였다. 채혈 직후 정밀도 및 정확도 평가를 위해 즉시 검사를 시행하였다. 검사종목은 백혈구수(WBC), 적혈구수(RBC), 혈색소 농도( $\mathrm{Hb})$, 평균 적혈구용적률 $(\mathrm{HCT})$, 평균 적혈구 용적 $(\mathrm{MCV})$, 평균 적혈구 혈색소 농도 $(\mathrm{MCHC})$, 평균 적혈구 혈색소 $(\mathrm{MCH})$, 적혈구 분포 지 수(RDW), 혈소판수(PLT), 혈소판 분포폭(PDW)의 혈구산정검사 10 종을 측정하였다. 혈구산정검사를 위해서 자동혈구분석기인 Heco5 (Dae Kwang Co., Korea) 를 이용하여 수행하였다. 정확도

Table 1. Information of $\mathrm{K}_{2}$ EDTA tubes and analysis items

\begin{tabular}{cll}
\hline Manufacture & \multicolumn{1}{c}{$\begin{array}{c}\text { Lot Number } \\
\text { (expiration date) }\end{array}$} & \multicolumn{1}{c}{ Analytes } \\
\hline S Co. & $31040287(15 / 11)$ & WBC, RBC, Hb, HCT, MCV, \\
& $31040291(15 / 11)$ & MCH, MCHC, RDW, PLT, \\
& $31040597(16 / 1)$ & PDW \\
B Co. & $4155545(15 / 10)$ & \\
& $4191554(15 / 11)$ & \\
G Co. & 4191579 (15/12) & \\
& D1306004 (14/12) & \\
& D131200V (15/6) & \\
& D141001I (16/4) & \\
\hline
\end{tabular}

Abbreviation: WBC, white blood cell; $\mathrm{RBC}$, red blood cell; $\mathrm{Hb}$, hemoglobin; HCT, hematocrit; MCV, mean corpuscular volume; $\mathrm{MCH}$, mean corpuscular hemoglobin; MCHC, mean corpuscular hemoglobin concentration; RDW, red cell distribution width; PLT, platelet; PDW, platelet distribution width.
평가를 위해 각 진공채혈관별 채혈 직후 각 진공채혈관에서 3회씩 반복측정(triplication) 하였다. 진공채혈관의 총 정밀도(total precision)는 지침에 따라 총 변이계수(total coefficient of variation, $\left.\mathrm{CV}_{\text {total }}\right)$ 를 계산하였다. 일반 통계분석은 Microsoft Excel (Microsoft Corp., Redmond, WA, USA)을 이용하고 수집된 자료의 분석은 SPSS 18.0 (SPSS Inc., Chicago, USA)를 이용하여 분석하였다. 각 그룹에 대한 평균과 표준편차로 분석하였다.

\section{결 과}

정밀도를 위한 평가에서는 동일 검체를 이용해 진공채혈관의 유 효기간 차이에 따른 혈구산정검사 결과를 분석하였다. 또한 각 3 사 의 진공채혈관을 이용해 혈구산정검사 10 종의 변이계수 (coefficient variation, CV) 값으로 비교 평가하였다(Table 2, 3).

유효기한이 1년 간격이 되는 다른 로트번호의 진공채혈관에 동 일 대상자로부터 얻은 혈액검체를 측정한 결과, $\mathrm{WBC}$ 와 PLT의 결 과 값에서 $0.24,0.21$ 순으로 다른 항목에 비해 가장 큰 변이계수를 보였다. 한편 가장 적은 변이계수 값을 보이는 것으로는 $\mathrm{RDW}$ 와

Table 2. Precision measured by $\mathrm{CV}$ of $\mathrm{G}$ tubes for expiration date (as followed by 2014, 2015, 2016 year)

\begin{tabular}{|c|c|c|c|c|c|c|}
\hline & Years & Mean & SD & Variance & $\mathrm{CV}$ & $\begin{array}{c}\mathrm{CV} \\
\text { mean }\end{array}$ \\
\hline \multirow[t]{3}{*}{$\mathrm{WBC}\left(10^{3} / \mu \mathrm{L}\right)$} & 2014 & 6.31 & 1.45 & 2.10 & 0.23 & \\
\hline & 2015 & 6.37 & 1.57 & 2.48 & 0.25 & \\
\hline & 2016 & 6.59 & 1.54 & 2.36 & 0.23 & 0.24 \\
\hline \multirow{3}{*}{$\operatorname{RBC}\left(10^{6} / \mu \mathrm{L}\right)$} & 2014 & 4.52 & 0.48 & 0.23 & 0.11 & \\
\hline & 2015 & 4.57 & 0.47 & 0.22 & 0.10 & \\
\hline & 2016 & 4.60 & 0.41 & 0.17 & 0.09 & 0.10 \\
\hline \multirow[t]{3}{*}{$\mathrm{HB}(\mathrm{g} / \mathrm{dL})$} & 2014 & 12.80 & 1.20 & 1.43 & 0.09 & \\
\hline & 2015 & 12.66 & 1.71 & 2.92 & 0.13 & \\
\hline & 2016 & 12.77 & 1.47 & 2.17 & 0.12 & 0.11 \\
\hline \multirow[t]{3}{*}{$\mathrm{HCT}(\%)$} & 2014 & 38.83 & 4.68 & 21.90 & 0.12 & \\
\hline & 2015 & 39.23 & 5.07 & 25.68 & 0.13 & \\
\hline & 2016 & 39.50 & 4.34 & 18.86 & 0.11 & 0.12 \\
\hline \multirow[t]{3}{*}{$\operatorname{PLT}\left(10^{3} / \mu \mathrm{L}\right)$} & 2014 & 260.50 & 51.47 & 2649.15 & 0.20 & \\
\hline & 2015 & 265.78 & 58.88 & 3466.33 & 0.22 & \\
\hline & 2016 & 276.88 & 61.68 & 3803.91 & 0.22 & 0.21 \\
\hline \multirow[t]{3}{*}{$\mathrm{MCV}(\mathrm{fL})$} & 2014 & 85.95 & 4.73 & 22.40 & 0.06 & \\
\hline & 2015 & 86.16 & 5.62 & 31.57 & 0.07 & \\
\hline & 2016 & 85.66 & 5.68 & 32.30 & 0.07 & 0.06 \\
\hline \multirow[t]{3}{*}{$\mathrm{MCH}(\mathrm{pg})$} & 2014 & 27.90 & 1.98 & 3.93 & 0.07 & \\
\hline & 2015 & 27.95 & 2.24 & 5.03 & 0.08 & \\
\hline & 2016 & 29.34 & 8.02 & 64.33 & 0.27 & 0.14 \\
\hline \multirow{3}{*}{ MCHC (g/dL) } & 2014 & 31.64 & 4.63 & 21.48 & 0.15 & \\
\hline & 2015 & 32.43 & 0.93 & 0.86 & 0.03 & \\
\hline & 2016 & 34.22 & 9.22 & 84.99 & 0.27 & 0.15 \\
\hline \multirow[t]{3}{*}{ RDW (\%) } & 2014 & 12.28 & 0.69 & 0.47 & 0.06 & \\
\hline & 2015 & 12.27 & 0.80 & 0.65 & 0.07 & \\
\hline & 2016 & 12.21 & 0.77 & 0.59 & 0.06 & 0.06 \\
\hline \multirow{3}{*}{ PDW (fL) } & 2014 & 10.42 & 1.61 & 2.61 & 0.15 & \\
\hline & 2015 & 10.71 & 0.61 & 0.37 & 0.06 & \\
\hline & 2016 & 10.60 & 0.60 & 0.35 & 0.06 & 0.09 \\
\hline
\end{tabular}

Abbreviation: See Table 1. 
Table 3. Precision measured by $\mathrm{CV}$ of individual G, B, S manufacture tubes as followed

\begin{tabular}{|c|c|c|c|c|c|c|}
\hline \multicolumn{2}{|c|}{ Manufacture } & \multirow{2}{*}{$\begin{array}{r}\text { Mean } \\
6.37\end{array}$} & \multirow{2}{*}{$\begin{array}{l}\text { SD } \\
1.57\end{array}$} & \multirow{2}{*}{$\begin{array}{r}\text { Variance } \\
2.48\end{array}$} & \multirow{2}{*}{$\frac{C V}{0.25}$} & \multirow[t]{2}{*}{$\begin{array}{c}\mathrm{CV} \\
\text { mear }\end{array}$} \\
\hline $\operatorname{WBC}\left(10^{3} / \mu \mathrm{L}\right)$ & G & & & & & \\
\hline & B & 6.51 & 1.82 & 3.32 & 0.28 & \\
\hline & $\mathrm{S}$ & 6.44 & 1.88 & 3.52 & 0.29 & 0.27 \\
\hline \multirow{3}{*}{$\mathrm{RBC}\left(10^{6} / \mu \mathrm{L}\right)$} & G & 4.57 & 0.47 & 0.22 & 0.10 & \\
\hline & $\mathrm{B}$ & 4.73 & 0.44 & 0.19 & 0.09 & \\
\hline & $\mathrm{S}$ & 4.63 & 0.45 & 0.21 & 0.10 & 0.10 \\
\hline \multirow[t]{3}{*}{$\mathrm{HB}(\mathrm{g} / \mathrm{dL})$} & $\mathrm{G}$ & 12.66 & 1.71 & 2.92 & 0.13 & \\
\hline & B & 13.00 & 1.51 & 2.27 & 0.12 & \\
\hline & $S$ & 12.62 & 1.62 & 2.63 & 0.13 & 0.13 \\
\hline \multirow[t]{3}{*}{ HCT (\%) } & G & 39.23 & 5.07 & 25.68 & 0.13 & \\
\hline & B & 40.68 & 4.15 & 17.18 & 0.10 & \\
\hline & $S$ & 40.51 & 4.71 & 22.22 & 0.12 & 0.12 \\
\hline \multirow{3}{*}{$\operatorname{PLT}\left(10^{3} / \mu \mathrm{L}\right)$} & G & 265.78 & 58.88 & 3466.33 & 0.22 & \\
\hline & B & 281.59 & 58.65 & 3439.24 & 0.21 & \\
\hline & $\mathrm{S}$ & 279.69 & 59.91 & 3589.50 & 0.21 & 0.21 \\
\hline \multirow[t]{3}{*}{$M C V(f L)$} & G & 86.16 & 5.62 & 31.57 & 0.07 & \\
\hline & B & 86.63 & 5.56 & 30.87 & 0.06 & \\
\hline & $\mathrm{S}$ & 87.22 & 5.63 & 31.65 & 0.06 & 0.06 \\
\hline \multirow{3}{*}{$\mathrm{MCH}(\mathrm{pg})$} & G & 27.95 & 2.24 & 5.03 & 0.08 & \\
\hline & B & 27.82 & 2.23 & 4.98 & 0.08 & \\
\hline & $\mathrm{S}$ & 27.35 & 2.40 & 5.75 & 0.09 & 0.08 \\
\hline \multirow[t]{3}{*}{ MCHC (g/dL) } & G & 32.43 & 0.93 & 0.86 & 0.03 & \\
\hline & $\mathrm{B}$ & 32.06 & 0.95 & 0.91 & 0.03 & \\
\hline & $\mathrm{S}$ & 31.32 & 1.54 & 2.37 & 0.05 & 0.04 \\
\hline \multirow[t]{3}{*}{ RDW (\%) } & G & 12.27 & 0.80 & 0.65 & 0.07 & \\
\hline & $\mathrm{B}$ & 12.29 & 0.71 & 0.50 & 0.06 & \\
\hline & $\mathrm{S}$ & 12.30 & 0.80 & 0.64 & 0.07 & 0.06 \\
\hline \multirow{3}{*}{ PDW (fL) } & G & 10.71 & 0.61 & 0.37 & 0.06 & \\
\hline & B & 10.57 & 0.62 & 0.38 & 0.06 & \\
\hline & $\mathrm{S}$ & 11.01 & 1.03 & 1.05 & 0.09 & 0.07 \\
\hline
\end{tabular}

Abbreviation: See Table 1.
$\mathrm{MCV}$ 로 모두 0.06으로 나타났다. 특히 유효기간 지난 진공채혈관 에서는 RBC, PDW가 0.11, 0.15로 유효기간 내, 유효기간이 1년 남은 진공채혈관에서 비해 가장 큰 변이계수를 보였다(Table 2). 이 들에 대한 검사 항목간에 상관성을 조사한 결과에서는 $\mathrm{WBC}, \mathrm{PLT}$, $\mathrm{RBC}$ 의 값이 의미있는 차이를 보였다 $(p<0.01)$ (Table 4). 이 외의 검사항목들의 상관성 조사에서는 유의한 차이를 나타내지 않았다 (data not shown).

또한 각 3 개 사의 유효기간내 진공채혈관을 동일검체로부터 비 교 평가한 결과, $\mathrm{WBC}, \mathrm{PLT}$ 가 0.27, 0.21로 가장 큰 변이계수를 보 였다. 한편 $\mathrm{MCHC}, \mathrm{MCV}, \mathrm{RDW}$ 가 $0.04,0.06,0.06$ 으로 가장 낮은 변이계수를 보였다. 특히 3 사 제품 중 $\mathrm{S}$ 사의 제품이 다른 타사 제품 들에 비해 변이계수가 상대적으로 높았다. 그 중 $\mathrm{WBC}, \mathrm{PDW}$ 가 $0.29,0.09$ 로 가장 높은 변이계수를 보였다(Table 3). 또한 이들에 대한 해당하는 검사 항목간에 상관성에 대해 조사한 결과 $\mathrm{WBC}$, $\mathrm{PLT}, \mathrm{PDW}$ 의 값에서 높은 유의 확률로 의미 있는 차이를 보였다 $(p<$ 0.01 ) 그러나 $\mathrm{G}$ 사와 $\mathrm{B}$ 사는 $\mathrm{PLT}, \mathrm{PDW}$ 의 값에서는 비교적 낮은 유 의 확률로 유의한 차이를 보였다 $(p<0.05)$ (Table 5). 이들 외의 검 사항목들의 상관성 조사에서는 유의한 차이를 나타내지 않았다 (data not shown).

Table 4. Correlation of G-tubes for expiration date (as followed by 2014, 2015, 2016 year)

\begin{tabular}{|c|c|c|c|c|c|c|c|c|c|c|c|c|c|}
\hline & & \multicolumn{3}{|c|}{ WBC } & \multicolumn{3}{|c|}{ PLT } & \multicolumn{3}{|c|}{ RBC } & \multicolumn{3}{|c|}{ PDW } \\
\hline & & 2014 & 2015 & 2016 & 2014 & 2015 & 2016 & 2014 & 2015 & 2016 & 2014 & 2015 & 2016 \\
\hline \multirow[t]{3}{*}{ WBC } & 2014 & 1 & & & & & & & & & & & \\
\hline & 2015 & $\begin{array}{l}.745^{\star *} \\
.000\end{array}$ & 1 & & & & & & & & & & \\
\hline & 2016 & $\begin{array}{l}.173 \\
.225\end{array}$ & $\begin{array}{l}.366^{\star \star} \\
.008\end{array}$ & 1 & & & & & & & & & \\
\hline \multirow[t]{6}{*}{ PLT } & 2014 & $.501^{\star *}$ & $.313^{*}$ & .146 & 1 & & & & & & & & \\
\hline & & .000 & .025 & .305 & & & & & & & & & \\
\hline & 2015 & $.313^{*}$ & $.336^{\star}$ & .163 & $.638^{\star \star}$ & 1 & & & & & & & \\
\hline & & .025 & .016 & .254 & .000 & & & & & & & & \\
\hline & 2016 & .164 & .242 & $.315^{\star}$ & .130 & $.464^{\star \star}$ & 1 & & & & & & \\
\hline & & .252 & .087 & .025 & .364 & .001 & & & & & & & \\
\hline \multirow[t]{6}{*}{$\mathrm{RBC}$} & 2014 & .117 & -.039 & -.099 & $.401^{\star \star}$ & .103 & -.173 & 1 & & & & & \\
\hline & & .413 & .786 & .490 & .004 & .473 & .225 & & & & & & \\
\hline & 2015 & -.157 & .087 & -.016 & .046 & 106 & -.230 & $.563^{\star *}$ & 1 & & & & \\
\hline & & .270 & .543 & .910 & .751 & .459 & .104 & .000 & & & & & \\
\hline & 2016 & -.102 & .030 & .139 & .006 & -.049 & .132 & .180 & $.449^{\star \star}$ & 1 & & & \\
\hline & & .477 & .836 & .329 & .965 & .734 & .357 & .206 & .001 & & & & \\
\hline \multirow[t]{6}{*}{ PDW } & 2014 & -.031 & -.144 & -.108 & -.071 & -.046 & -.009 & .095 & -.127 & -.118 & 1 & & \\
\hline & & .829 & .313 & .452 & .618 & .747 & .950 & .506 & .374 & .409 & & & \\
\hline & 2015 & .029 & -.005 & .009 & -.275 & $-.378^{\star \star}$ & $-.297^{\star}$ & .198 & .147 & .109 & .013 & 1 & \\
\hline & & .839 & .971 & .952 & .051 & .006 & .035 & .164 & .305 & .446 & .927 & & \\
\hline & 2016 & .025 & -.102 & .057 & -.056 & $-.279^{\star}$ & $-.381^{\star *}$ & .213 & .141 & .110 & -.233 & $.377^{\star \star}$ & 1 \\
\hline & & .859 & .477 & .692 & .696 & .047 & .006 & .133 & .325 & .441 & .100 & .006 & \\
\hline
\end{tabular}

Abbreviation: See Table 1, ${ }^{\star *} p<0.01,{ }^{\star} p<0.05, \mathrm{r}(p)$. 
Table 5. Correlation of $\mathrm{G}^{-}$, B-, S-tubes as followed

\begin{tabular}{|c|c|c|c|c|c|c|c|c|c|c|}
\hline & & \multicolumn{3}{|c|}{ WBC } & \multicolumn{3}{|c|}{ PLT } & \multicolumn{3}{|c|}{ PDW } \\
\hline & & G & B & $S$ & G & B & $S$ & G & B & $\mathrm{S}$ \\
\hline \multirow[t]{3}{*}{ WBC } & G & 1 & & & & & & & & \\
\hline & B & $\begin{array}{l}.454^{\star \star} \\
.001\end{array}$ & 1 & & & & & & & \\
\hline & $\mathrm{S}$ & $.808^{\star \star}$ & $.381^{\star \star}$ & 1 & & & & & & \\
\hline \multirow{6}{*}{ PLT } & G & $.336^{*}$ & $\begin{array}{l}.000 \\
.172\end{array}$ & .151 & 1 & & & & & \\
\hline & & .016 & .229 & .291 & & & & & & \\
\hline & B & .169 & $.303^{*}$ & .255 & $.277^{\star}$ & 1 & & & & \\
\hline & & .235 & .031 & .071 & .049 & & & & & \\
\hline & $\mathrm{S}$ & .273 & $.311^{\star}$ & .206 & $.795^{\star \star}$ & $.450^{\star \star}$ & 1 & & & \\
\hline & & .053 & .026 & .148 & .000 & .001 & & & & \\
\hline \multirow[t]{6}{*}{ PDW } & G & -.005 & -.256 & -.066 & $-.378^{\star \star}$ & $-.294^{*}$ & $-.569^{\star \star}$ & 1 & & \\
\hline & & .971 & .070 & .647 & .006 & .036 & .000 & & & \\
\hline & B & .101 & .081 & .023 & -.161 & $-.319^{*}$ & -.124 & $.299 *$ & 1 & \\
\hline & & .481 & .573 & .872 & .258 & .023 & .385 & .033 & & \\
\hline & $\mathrm{S}$ & -.096 & -.264 & -.151 & $-.350^{\star}$ & $-.445^{\star *}$ & -.460 ** & $.739^{\star \star}$ & $.401^{\star \star}$ & 1 \\
\hline & & .501 & .061 & .289 & .012 & .001 & .001 & .000 & .004 & \\
\hline
\end{tabular}

Abbreviation: See Table 1, ${ }^{\star \star} p<0.01,{ }^{*} p<0.05, \mathrm{r}(p)$.

\section{고 찰}

인체의 혈액은 질병 및 예방에 대한 정보를 제공하는 중요한 체 액이다. 이 정맥혈을 채혈하는 진공채혈관의 상태 및 유통기한, 보 관상태, 유통상태, 제조상태, 장비의 분석방법 등에 따라 검사 결과 에 영향을 미칠 수 있으며[7-9], 정밀도와 정확도를 객관적으로 평 가하고 오류를 최소화하여 신뢰할 수 있는 검사결과를 얻기 위해서 는 유통되는 제품에 대한 기초평가가 이루어진 진공채혈관을 이용 해야 할 것이다[10]. 최근에 병원들의 소모성 원가를 줄이기 위해 다양한 저가형 진공채혈관들이 수입되어 국내의료시장에 들어와 사용하는데 있어서 기초적이며 객관적인 평가 수행 여부를 알아볼 수 없는 현실이며 묵시적으로 의료기관 현장에서는 사용되고 있다. 따라서 여러 제품들의 도입으로부터 검사실 수준에서 검사 결과에 미치는 영향을 평가하여 이러한 기초정보를 통해 분석전의 오차를 줄이기 위한 정도관리 차원의 분석평가가 선행되어져야 할 것으로 사료된다. 최근 국내 여러 연구자들이 정맥혈 채혈을 위한 진공채 혈관의 성능에 대해 평가해 왔으나 평가방법에 있어서 여러 한계를 제시하고 있다 [5,6]. 기존의 연구에서는 규격화된 진공채혈관의 평 가가 일회성 측정 결과로 평가했기 때문에 신뢰할 만한 정확도, 정 밀도를 평가할 수 없었다는 점을 제한하고 있다.

본 연구에서는 분석 장비별 평가, 진공성능의 평가, 안정성 평가, 무균성 평가, 다양한 검사항목에 대한 평가가 배제된 제한점을 가 지고 있다.

Lee 등은 정밀도 평가 결과에서 $\mathrm{S}$ 사는 $\mathrm{MCHC}, \mathrm{PDW}$, basophil, reticulocyte 등 4종목에서 6건의 'Not allowable' 판정을 받았고, $\mathrm{B}$ 사의 경우 $\mathrm{MCHC}, \mathrm{PDW}$, basophil, reticulocyte, $\mathrm{HbA1c}$ 등 5종
목에서 7건의 'Not allowable' 판정을 받은 것을 참조했을 때[6] 본 연구에서도 PDW의 결과에서 유의적인 차이를 보이는 것으로 보 아 항응고제의 영향으로 인한 PDW의 결과에는 제조사별 차이가 있을 것으로 사료되나 검사의 임상적 의의 측면에서는 큰 영향을 미치지 않을 것으로 보인다.

최근 연구에서는 동일 회사의 진공채혈관 제품 중에서 유리재질 과 플라스틱 재질간의 비교평가에서 특이한 차이가 없는 동일한 검 사 결과를 나타냈으며 단지 72 시간 이상의 혈액검체의 보관에서는 보체인자들이 증가하기 때문에 48시간 이내 사용을 권고하였으며 48 시간이상 보관 후 검사수행의 경우는 $-20^{\circ} \mathrm{C}$ 보관을 추천하는 것 으로 보고하였다[11].

또한 혈청의 수집을 위한 진공채혈관에서는 응고 반응 속도 또 는 종말점에는 영향을 주지 않기 때문에 더 일관성이 있으나 혈장 의 수집을 위한 진공채혈관은 고분자의 추가로 인해 공격적인 혈액 시료의 활성을 감소시켜 $\mathrm{EDTA}$ 와 같은 첨가제로 응고 과정에서 요 구되는 혈소판의 방출물질로 인해작은 펩티드 및 킬레이트 물질이 용출되어 영향을 미치게 되는 것으로 알려져 있다[12]. 이와 관련하 여 본 연구에서는 혈액응고와 관련된 인자를 측정하지 못했지만 추 후에는 보고된 지침[13]에 맞는 혈액응고인자의 검사를 수행하여 분석평가를 해야 할 것으로 사료된다.

분석평가의 통계적 관점에서는 RST (rapid separate tube)와 SST (serum separate tube)를 비교평가 한 이전의 보고[14]에서 결과분석처럼 개체내 변이계수(within-subject coefficients of variation, $\mathrm{CVw}$ )와 개체간 변이계수(between-subject coefficients of variation, $\mathrm{CVg}$ )를 조사하는 개념을 기반으로[15]. 각 진 공채혈관별 바이어스의 산출을 위한 평균차(mean difference (\%)) 
는 [(시험 채혈관의 평균-대조 시험관의 평균/대조 시험관 평 균) $\times 100]$ 을 활용하여 평가하는 방식이 정밀성과 정확성을 높이는 기법으로 사료된다.

결론적으로 본 연구에서 평가한 $\mathrm{S}$ 사의 진공채혈관은 정밀도 평 가에서 객관화 된 표준 기법을 통해 조사를 수행해야 할 것이며, $\mathrm{B}$ 사의 진공채혈관과 비교하여 변이계수가 높게 나타난 수준의 성능 을 보이므로 실제 임상검사에 사용하는데 있어서 유효기간의 선택 과 검사항목 별 변이계수가 다르다는 것을 참고하여 사용하여야 할 것으로 사료된다. 이는 변이계수가 높은 수준으로 차이를 보이는 부분은 통계학적인 분석을 통해 검증해야 할 것으로 보이며, 진공 채혈관의 유용성을 판단하기 위해서는 본 연구의 수정 보완이 필요 할 것이며 이는 향후 평가지침의 표준화 과정을 위한 기초정보를 제공할 것으로 보인다.

\section{요 약}

분석전 변이로 인하여 검사실은 오류에 직면하게 되고 많은 요 인들은 환자의 검사결과에 영향을 미치게 된다. 다양한 진공채혈관 은 신속하게 분리하고 방치된 검체의 용혈을 방지한다. 그러나 진 공채혈관의 상태에 따라 몇 가지 제한점들이 발생하는데 이러한 문 제점을 알아보기 위해 다양한 진공채혈관을 이용해 혈구산정검사 로 비교 평가하였다. 유통기한별 검사결과에서는 백혈구 $(\mathrm{WBC})$ 와 혈소판(PLT)의 값에서 $0.24,0.21$ 로 큰 변이계수를 나타냈고 상관 성에서는 백혈구(WBC), 혈소판(PLT), 적혈구(RBC)의 값이 유의 성을 보였다 $(p<0.01)$. 한편 각 3 사의 비교평가에서는 백혈구 $(\mathrm{WBC})$, 혈소판(PLT)의 값에서 $0.27,0.21$ 로 가장 큰 변이계수를 나 타냈고. 상관성에서는 각 3 사가 모두 백혈구(WBC), 혈소판(PLT), 혈소판분포폭(PDW)의 값에서 높은 유의한 차이를 보였다 $(p<$ 0.01 ) 그러나 $\mathrm{G}$ 사와 B사는 혈소판(PLT), 혈소판분포폭(PDW)의 값에서는 낮은 유의한 차이를 보였다 $(p<0.05)$. 결론적으로 진공 채혈관의 상태에 따른 분석의 안정성을 위해 적절한 진공채혈관의 분석평가가 이루어져야 한다.

Acknowledgements: 이 논문은 2016년도 남서울대학교 학술연 구비 지원에 의해 연구되었음.

Funding: None

Conflict of interest: None

\section{References}

1. NCCLS. Procedures for the handling and processing of blood specimens; Approved guideline-second editions. NCCLS document H18-A2. Wayne, Pennsylvania: National Committee for Clinical Laboratory Standards; 1999.

2. CLSI. Validation and verification of tubes for venous and capillary blood specimen collection; Approved guideline. CLSI document GP34-A. Wayne, Pennsylvania: Clinical and Laboratory Standards Institute; 2010.

3. CLSI. Method comparison and bias estimation using patient samples; Approved guideline-second edition (interim revision). CLSI document EP09-A2-IR. Wayne, Pennsylvania: Clinical and Laboratory Standards Institute; 2010.

4. Li Z, Feng Z, Yan C, Yan R. Evaluation of BD Vacutainer SST ${ }^{\mathrm{TM}}$ II plus tubes for common tumor marker tests by Roche Diagnostics Modular E 170 analyzer. J Clin Lab Anal. 2010;24(6):418-421.

5. Won EJ, Shin MG, Jang MJ, Cho D, Kee SJ, Kim SH. et al. Comparison between V-Tubes and BD Vacutainer tubes for use in laboratory tests. Lab Med Online. 2012:3(3):145-154.

6. Lee JH, Cha YJ, Lee DS, Kim SY. A comparison of the performance of Soyagreentec Ampulab EDTA and sodium citrate tubes with that of BD vacutainer tubes. Lab Med Online. 2015:5(2): 92-100.

7. Hong SB, Kim JS, Shin KS. The effect of the storage duration and temperature of EDTA Specimen for CBC and WBC differential count in SE-9000 automated cell counter. Korean J Clin Lab Sci. 2006;38:147-151.

8. Lim YK, Kim CH, Kang YH, Park CJ, Chi HS. IMI channel and HPC mode evaluation in CBC autoanalyzer SE-9000. Korean J Clin Lab Sci. 2000;32:48-52.

9. Bowen RA, Hortin GL, Csako G, Otanez OH, Remaley AT. Impact of blood collection devices on clinical chemistry assays. Clin Biochem. 2010;43:4-25.

10. CLSI. Tubes and additives for venous blood specimen collection; Approved standard-fifth edition. CLSI document H1-A5. Wayne, Pennsylvania: Clinical and Laboratory Standards Institute; 2003.

11. Li Z, Yan C, Yan R, Zheng X, Feng Z. Evaluation of BD Vacutainer SSTTM II plus tubes for special protein testing. J Clin Lab Anal. 2011;25(3):203-206.

12. Drake SK, Bowen RA, Remaley AT, Hortin GL. Potential interferences from blood collection tubes in mass spectrometric analyses of serum polypeptides. Clin Chem. 2004;50(12):2398-401.

13. CLSI. Collection, transport, and processing of blood specimens for testing plasma-based coagulation assays and molecular hemostasis assays; Approved guideline-fifth edition. CLSI Document H21-A5. Wayne, Pennsylvania: Clinical and Laboratory Standards Institute; 2008.

14. Kocijancic M, Cargonja J, Delic-Knezevic A. Evaluation of the BD Vacutainer( $($ ) $)$ RST blood collection tube for routine chemistry analytes: clinical significance of differences and stability study. Biochem Med (Zagreb). 2014;24(3):368-375.

15. Ricos C, Alvarez V, Cava F, Garcia-Lario JV, Hernandez A, Jimenez CV. et al. Current databases on biologic variation: pros, cons and progress. Scand J Clin Lab Invest. 1999;59(7): 491-500. 